\title{
Academics' ideals and universities' third mission
}

\section{Introduction}

Although ideological debate continues over the merits of what Paul David (David 2002) has called the 'economic instrumentalism' that characterises contemporary science and technology policy discussions, there can be little doubt that the 'entrepreneurial university' is “in vogue" (D'este and Perkmann 2011, p. 316). Indeed, and despite ongoing conceptual and practical ambiguities (Sam and Van Der Sijde 2014), at least one prominent observer has gone further, arguing that the role of universities continues to evolve: through the entrepreneurial university towards the university for the entrepreneurial society (Audretsch 2014). Here the emphasis is broadened beyond technology transfer and academic spin-offs, to the provision of leadership, creativity and the enhancement of 'entrepreneurial capital' in society at large. This is a particular spin on the more familiar concept of a 'third mission', centred broadly on universities' contributions to socio-economic development (Koryakina, Sarrico, and Teixeira 2015).

Of course, a larger part of university science has always both been driven by the pursuit of basic understanding and inspired by considerations of use (Loi and Di Guardo 2015). It is the institutionalising of universities' third missions that is a more recent phenomenon (Rolfo and Finardi 2014); accelerated by increased funding pressures and growing managerialism, and a by a broader attachment to the entrepreneurial zeitgeist. In this, 'knowledge capitalization' is placed on par with knowledge production and dissemination (Goldstein 2010) and universities are positioned as "engines of economic growth" (Tartari, Perkmann, and Salter 2014).

Yet, while policy-makers and university administrators appear unified in their conviction, the returns to the third mission may be best characterised as inconsistent. In this light, Hmieleski and Powell (2018, p. 44) point to the top down nature of many initiatives, which frequently neglect the "nuanced differences in the goals, motives and experiences of academic scientists". This echoes earlier concerns that a more developed understanding of university scientists is missing from conversations around universities' third missions (Jain, George, and Maltarich 2009). Although Etzkowitz (2002) famously observed MIT scientists' attitudes to entrepreneurial science evolving from opposition, to acquiescence, to acceptance, many recent studies continue to highlight the persistence of different perspectives on the third mission within universities (Philpott et al. 2011). Despite reforms to increase their 'manageability' (de la Torre, Rossi, and Sagarra 2018), most universities remain comparatively flat organisations (Benneworth, de Boer, and Jongbloed 2015). Universities are professional bureaucracies; reliant upon highly skilled employees conditioned to exercise initiative and cherish autonomy (Perkmann et al. 2013) ${ }^{1}$.

\footnotetext{
${ }^{1}$ Of course, this is not a universal perspective. For instance, in a recent polemic, Oleksiyenko $(2018$, p.193) charges that 'In the quest to bring down the 'ivory tower' as advocated by the 'knowledge factory' designers of the 1990s, the managers of the global neoliberal economy have largely succeeded in creating, in their parlance, 'knowledge workers' who are tireless, compliant and expendable".
} 
Reassuringly, empirical work on academic entrepreneurship, specifically, and universities' third missions, more generally, has increasingly adopted a micro focus; taking the individual university scientist as the unit of analysis. This work has shed light on, inter alia, the role of prior experience, seniority, age, gender, research focus and academic discipline on engagement in third mission activities (e.g. Abreu and Grinevich 2012; D'este and Perkmann 2011; Clarysse, Tartari, and Salter 2011; Haeussler and Colyvas 2011). That is, it has been concerned with propensities towards action. However, we believe that an important prior step has had limited consideration. In line with the theory of planned behaviour (TPB), it is likely that academics' attitudes towards the evolving role of universities predict intentions and actions (Hmieleski and Powell 2018; Goethner et al. 2012). As Mangematin and colleagues (2014, p. 9) observe, "...academia needs scholars who are willing to take risks, who have visions and expectations, and who are able to shape organisations to enact the environment". Yet, studies of academics' attitudes are relatively rare. Where they exist, the tendency is to conflate motivation with attitude (e.g. Lam 2011; lorio, Labory, and Rentocchini 2017). Although these studies have been important in differentiating extrinsic and intrinsic motivations, the broader issue of academic 'identity' has been less closely studied.

It is common to draw a distinction between the 'traditional' scientist, committed to 'Mertonian' norms of open science, and the 'entrepreneurial' scientist, aligned more closely with third mission ideals (e.g. Lam 2011; Watermeyer 2015), with the former painted as obstacles to the development of a consistent third mission. This dichotomy misrepresents the wide variety of perspective on our campuses (Owen-Smith and Powell 2001; Jain, George, and Maltarich 2009; Goldstein 2010). Crucially, it sheds limited light on the micro-foundations of relative attachment to these ideals; with attachment, or acceptance, a key antecedent of engagement (Grimaldi et al. 2011). Understanding the bases of opposition, acquiescence or acceptance is likely to be critical in progressing both rhetoric and practice associated with university socio-economic engagement.

To this end, the current study takes advantage of extensive data collected as part of the Survey of Knowledge Exchange Activity by UK Academics (2012-2015)² (Hughes et al. 2017). While much of the prior literature has examined faculty engagement in third mission activities, we examine a prior step. That is, our concern is with faculty attitudes towards the broader implications of a university third mission. In this, we explore the career profiles, personal characteristics and perspectives on career development that associate with a commitment to third mission principles and, in the converse, we identify those academics least attached to the third mission. This study makes a significant empirical contribution to the third mission literature and to policies and practices of third mission. We observe a dearth of studies focusing on the micro-foundations of the third mission, particularly regarding the dispositions of the key actors, viz. individual faculty members. This study contributes to filling this need. To the extent that third mission activities are undertaken by individual faculty members (Cesaroni \& Piccaluga, 2016), understanding their attitudes towards the evolving role of universities in economic systems will aid in crafting policies and strategies for successful implementation. The insights from the study enable a deeper understanding of the profile of faculty members who are 'ready and willing' to contribute to the achievement of third

\footnotetext{
${ }^{2}$ Our thanks go the UK Data Service and to the Centre for Business Research at the University of Cambridge for access to the survey data.
} 
mission objectives. These insights may be used to guide recruitment, development, compensation, and incentive policies of universities, the nature of collaboration and interactions with non-academic actors within society, and the nature of academic programs offered. The insights may also help universities overcome the nagging challenge of how best to organize and manage their third mission activities in order to achieve their objectives.

The paper is structured as follows: Section 2 outlines the challenges that the evolution of universities' third mission has placed on academic identity and the consequences for the success of the third mission agenda. We draw on an extensive empirical literature on the micro-foundations of academic entrepreneurship to develop hypotheses on the foundations of perspectives on the role of universities; section 3 provide further details on the survey and outlines our approach to analyses; section 4 presents the results of our analyses; finally, section 5 reflects on the implications of our findings for academics, university administrators and policy makers.

\section{Academic identity and perceptions on the role of the university}

In general terms, recent empirical evidence suggests that academic scientists are more motivated by academic accolades than by pecuniary rewards (Hmieleski and Powell 2018). In Lam's (2011) terms, they prefer 'ribbons' and 'puzzles' to 'gold'. The literature is fairly consistent in establishing the prevalence of intrinsic over extrinsic motivations; with Bruneel, d'Este and Salter (2010), for example, arguing that academics' acceptance of lower wages is indicative of intrinsic motivation and Horta and Santos (2016, 1245 ) identifying scientific ambition and peer recognition as the key drivers for "most researchers". In general terms, this is consistent with evidence, at both the individual and institutional levels, of the continuing primacy of the first and second (teaching and research) missions over the third mission (e.g. Lockett, Kerr, and Robinson 2008; Loi and Di Guardo 2015).

From this, some observers have inferred that the rules for academic assessment and career progression, which revolve around publications, research funding and teaching, are the primary impediments to greater engagement and entrepreneurship (Koryakina, Sarrico, and Teixeira 2015). However, this, in turn, underestimates the strength of a traditional academic identity, associated with a commitment to the norms of open science, publication and broad-based dissemination. In this vein, Hmieleski and Powell (2018, p. 59) reflect on extensive evidence of "...the desire of scientists to maintain their professional identity - the beliefs, conceptions, expressions, and qualities that classify a person as being a member of a particular occupational group - as a traditional academic rather than a businessperson". Similarly, Jain, George and Maltarich (2009, p. 924) contemplate the sacrifice involved in assuming an entrepreneurial identity in terms of the loss of a prior identity that is "cherished, and stable". Watermeyer (2015, p. 334) goes further; indicating that respondents in his study of UK academics believed that public engagement "had diluted and despoiled their reputation as researchers". Indeed, the emergence of the 'engaged' university has seen identity crises manifest at the institutional as well as the individual level (Chantler 2016). In short, it is not career structures and reward systems, per se, that impede acceptance of the third mission. Rather, there remains resistance from many academics to the ideology of the third mission 
(D'este and Perkmann 2011). Indeed, Goldstein (2010, p. 107) suggests that a "substantial majority of faculty in the humanities and social sciences have not 'acquiesced' to the entrepreneurial turn".

This resistance appears based on fundamental, normative concerns about the appropriateness and legitimacy of universities' engagement in a broad swathe of activities and the implications for the traditional Mertonian values of communism, universalism, disinterestedness and organised skepticism (Merton 1942). Many commentators believe that "...there is a fundamental tension in the notion of a third mission. Most university systems have traditionally drawn their internal and external legitimacies from the fact that their activities were somewhat disconnected or decoupled from societal affairs" (Pinheiro, Langa, and Pausits 2015, p. 227). Coupled with the specific charge that universities' third missions may actually retard the diffusion of valuable knowledge and weaken the quality of basic research (Nelson 2001), it is hardly surprising that the third mission is seen by some as a "threat to the purpose of the university" (Philpott et al. 2011, p. 168).

Given continued ambivalence towards the third mission and its basis in the mindsets of the variety of academics on campus (Jain, George, and Maltarich 2009), we begin by constructing hypotheses that seek to understand the sources of antipathetic dispositions. In doing this, we borrow from the extensive empirical literature that has examined the micro-foundations of academic entrepreneurship. Our contention is that this work has elided an important step. The work we draw on has largely considered only the direct effects of human capital and economic variables in stimulating engagement (Goethner et al. 2012). That is, it has been concerned with how various antecedent characteristics are manifest in third mission behaviours. However, it is likely that these antecedents first shape attitudes and social norms that, subject to perceived control, shape intentions and actions in turn. And, where they do not, this implicates impediments to action that may be germane. By exploring dispositions (i.e. proclivities rather than propensities), we believe that this approach contributes to "a better understanding of the psychological foundations of university science commercialization" (Hmieleski and Powell 2018, p. 44) and allows us to nudge the discussion forward. As "uncertain and transitional" funding environments increasingly require key scholars to adopt strategic postures that balance "conformance and a longiness for scientific freedom" (O'Kane et al. 2015, p. 201), a more developed understanding of acceptance of the former and strength of attachment to the latter will be invaluable.

\subsection{Disciplinary Considerations}

Perhaps the most consistent observation in the empirical literature reflects on the substantial variety in the extent of external engagement across academic disciplines (Bekkers and Bodas Freitas 2008; Abreu and Grinevich 2012). In general terms, the evidence suggests that academics in engineering, the life sciences and the physical sciences are more likely to have engaged in third mission activities than are academics in the social sciences or, in particular, the humanities (Goldstein 2010). However, this engagement may, in turn, be reflective of systematic differences in motivation across disciplines (Cunningham et al. 2016; Sauermann, Cohen, and Stephan,2010). An academic's discipline establishes an important context that reflects common work practices and ways of knowing. It also shapes attitudes and inclinations towards 'entrepreneurial science' (Lam 2011; D'Este and Patel 2007). Accordingly, and despite 
suggestions that universities' traditional focus on a narrow group of disciplines may represent a missed opportunity (Hmieleski and Powell 2018), we hypothesise that:

H1: Pro third mission attitudes are likely to be least common among faculty members in the humanities and most common in engineering, health and the physical sciences.

\subsection{Research focus}

In a rather straightforward argument, we anticipate that academics engaged in applied or user-inspired research are more likely to hold attitudes towards the role of the university that is consistent with third mission ideals. This is research in Pasteur's Quadrant (Stokes 1997); inspired by considerations of use as well as by basic understanding. It is for this reason that Stephan et al. (2007) observe higher patenting rates in medical schools and among engineers - beyond disciplinary considerations. To paraphrase Calderini, Franzoni, and Vezzulli (2007. p. 317), it would not be particularly surprising to find that scientists working on applied or user-inspired research would be more likely to associate with third mission ideals than those working on basic research. Certainly, such a finding would be consistent with revealed behaviours. Abreu and Grinevich (2012), for instance, using data from the 2008 iteration of this survey, observe that academics identifying as engaged in user-inspired basic research or applied research were more likely to engage in a broad range of 'entrepreneurial' activities than those identifying as engaged in basic research. However, it also speaks to the extent that "some academics are attitudinally predisposed to commercialise their findings or possess prior knowledge that makes them more capable of recognizing entrepreneurial opportunity" (Cunningham et al. 2016, p. 784; see also Jain, George, and Maltarich 2009). Accordingly, we hypothesis that:

H2: Pro third mission attitudes are likely to be most common among faculty members engaged in applied or user-inspired basic research.

\subsection{Rank and age}

The literature on academic entrepreneurship often conflates issues of seniority and age, with the terms "junior" and "younger" used interchangeably (Tartari, Perkmann, and Salter 2014). Following this, the general evidence is that younger and more junior scientists are less likely to engage in technology transfer or entrepreneurial activities (Lam 2011). However, the rationalisation of this finding is less settled. For instance, some authors draw on life cycle models of academic careers to suggest that the career focus of early stage academics is on publishing and teaching rather than knowledge transfer or commercialisation (Link, Siegel, and Bozeman 2007; Carayol 2007). Whether this is about attitude or expediency is less clear. And, of course, that is apropos our current concerns. An alternative approach may be to articulate the issue in terms of resources and opportunities. In this perspective, junior and younger academics may be more open to the third mission (Ambos et al. 2008), but their lack of experience, human capital and reputation retard their engagement. Although they are more likely to have been "socialised into the emerging entrepreneurial paradigm" (Lam 2011), the precarious nature of an early stage academic career and the requirements of tenure and early progression work against external engagement. In contrast, 
older and more senior academics operate in wider networks, control more organisational resources and have more freedom to engage in third mission activities (Tartari, Salter, and D'Este 2012; Tartari, Perkmann, and Salter 2014). This leads junior scientists to act, at best, as project managers, with more senior colleagues taking on the role of scientific entrepreneur by bring about new combinations of knowledge and resources (Casati and Genet 2014). Accordingly, and despite general evidence of a higher propensity to external engagement associated with increasing age and rank, we draw on evidence that the relative attractiveness of engagement decreases with scientists' age and rank (Bercovitz and Feldman 2008; Fritsch and Krabel 2012), to hypothesise that:

H3: Pro third mission attitudes are likely to be least common among older and more senior academics and most common among younger and more junior academics.

\subsection{Gender}

A usual suspect in the literature on academic entrepreneurship is the issue of gender. Here it is typical to observe both a lower incidence of entrepreneurship, either narrowly or broadly defined, and, more occasionally a lower proclivity to entrepreneurship on the part of female academics (Hmieleski and Powell 2018). For instance, Haeussler and Colyvas (2011) find that women in the life sciences are less likely than men to either patent or found a business. On the softer side of entrepreneurship, Grimpe and Fier (2010), in their study of German and American university scientists, observe that female scientists were significantly less likely to engage in informal technology transfer activities than were male scientists. Both these patterns are confirmed by Abreu and Grinevich (2012). While Colyvas et al. (2012) argue that gender differences in engagement are largely explained by differences in publication record, history of funding and rank, such that the issue is one of resources and opportunities rather than disposition, the general tenor of the literature is in the opposite direction. In this vein, Abreu and Grinevich (2017) note arguments that female academics face greater pressures to balance tenure requirements and family responsibilities; they have less commercial experience; and, are less likely to belong to networks that include industrial partners. On balance, this leads us to hypothesise that:

H4: Female academics are less likely to be attached to third mission ideals.

\subsection{Experience}

In the academic entrepreneurship literature, it is common to point to the association between prior entrepreneurial experience and engagement in academic entrepreneurship (Krabel and Mueller 2009; Hoye and Pries 2009). This is the notion that academic entrepreneurship occurs at the boundaries of different scientific and professional experiences (Guerrero, Cunningham, and Urbano 2015). In this vein, Abreu and Grinevich (2012), for instance, find that having owned a small company in the past also positively associates with engagement in softer forms of academic engagement. More generally, prior work experience outside of a university environment is taken "as a marker of useful human capital for science commercialisation" (Hmieleski and Powell 2018, p. 56; see also Shane et al. 2015). Analogously, Dietz and Bozeman (2005) observe that academics who had spent a larger part of their careers in industry 
attracted more funding and registered more patents. All of this speaks to propensities to engage in third mission activities. We extrapolate from this and anticipate that experience working with the challenges of industry and with society outside of the university will associate with great sympathy for the ideals of the third mission and we hypothesise that:

H5: Academics who have no experience of working outside of the university environment are less likely to be attached to third mission ideals.

\subsection{Incentives}

Our final concern is with academic incentives. As noted above, prevailing university incentives are frequently portrayed as significant barriers to the advancement of the third mission (Koryakina, Sarrico, and Teixeira 2015). Simply put, in the traditional academic model publication is the primary signal of achievement. Teaching may be valued to varying degrees at various institutions, but third mission activities fall far behind. This creates a challenge for the advancement of the third mission which requires that "specific motivations to do KTT activities should be coherent with the general motivations that university scientists have in their job" (Labory, lorio, and Rentocchini 2015, p. 5). In line with our present purpose, Lam (2011) reflects on the implications of self-determination theory and argues that the manner in which academic scientists respond to different kinds of incentives is influenced by the degree of congruence between their personal values and the targeted activity. Moreover, individual academic's attitudes towards behaviours and achievement are likely to be highly influenced by prevailing local norms

(Tartari, Perkmann, and Salter 2014). These, in turn, are likely to be manifest in institutional rewards systems. This leads us to hypothesise that:

H6: Academics who believe that their university primarily rewards research and, to a lesser extent, teaching are less likely to be attached to third mission ideals.

\section{Data and Measures}

Our analysis draws on data from the Survey of Knowledge Exchange Activity by UK Academics (2012-2015). The design of the survey followed a previous round in 2009. Data from this previous survey have allowed researchers to make important contributions to our understanding of academic engagement and entrepreneurship (e.g. Abreu and Grinevich 2012, 2014; Abreu et al. 2016; Abreu and Grinevich 2017).

Details on the survey design, survey methodology and broad patterns of responses are reported in Hughes et al. (2016). In broad terms, 140,312 UK academics were surveyed via email in waves of 10,000 between March and September 2015. After excluding 'undeliverable' and 'ineligible' responses, a final eligible sample of 131,088 academics remained. In addition to the initial invitation to participate, each potential 
respondent received email prompts after 10 days, and after a further 7 days. From this, 18,177 complete responses were received (a response rate of $13.9 \%{ }^{3}$ ).

While the invitation email indicated that the survey team were interested in responses regardless of whether the individual academic had engaged in interactions with external organisations, it is clearly possible that the likelihood of responding may be related to experience with engagement. To explore bias, the survey team compared early and late respondents, and complete and incomplete respondents. The results suggested small quantitative differences indicative of "a small upward bias...in the estimated level of interactions with external organisations" (Hughes et al. 2016, p. 98). The survey team also compared the sample frame and respondents with aggregate data on the population of UK academics available from the UK Higher Education Statistics Agency. The analysis suggests that respondents over-represent professors ${ }^{4}$ and academics over the age of 50, and underrepresent academics in the arts and humanities. The implication is, again, a likely upward bias in the extent of engagement in academic entrepreneurship and external knowledge exchange.

\subsection{Measures}

Our dependent variables are constructed from responses to a question that asks respondents the extent to which they agree or disagree with a series of 7 "...statements about relationships between higher education institutions and external organisations", on a 5 point scale ranging from strongly disagree to strongly agree. This was the final question (Q.43) in a questionnaire concerned with various forms of external engagement and knowledge exchange. In order, the statements were:

1. Academia should focus on basic research and should not be concerned with its actual or potential application ("Basic Research").

2. Academic freedom is of fundamental importance to the future wellbeing of society ("Academic Freedom").

3. Higher education has a key role to play in increasing the competitiveness of business in the UK ("Competitiveness").

4. The main purpose of university teaching should be to prepare students for the labour market ("Labour Market").

5. UK business does not have the capacity to use research effectively ("Capacity").

6. Over the past few years, universities have gone too far in attempting to meet the needs of industry to the detriment of their teaching and research roles ("Too Much").

7. Over the past few years universities have done too little to increase their relevance to society or contribution to economic development ("Too Little").

\footnotetext{
${ }^{3} 162$ students also provided complete responses and there were a further 6,633 incomplete responses. These have been set aside.

${ }^{4}$ In the UK it is still common for academic ranks to be designated as professor, senior lecturer and lecturer. These are broadly equivalent to full professor, associate professor and assistant professor. Since the survey is of UK academics, we employ the former language.
} 
Figure 1 Attitudes towards the 'Third Mission'

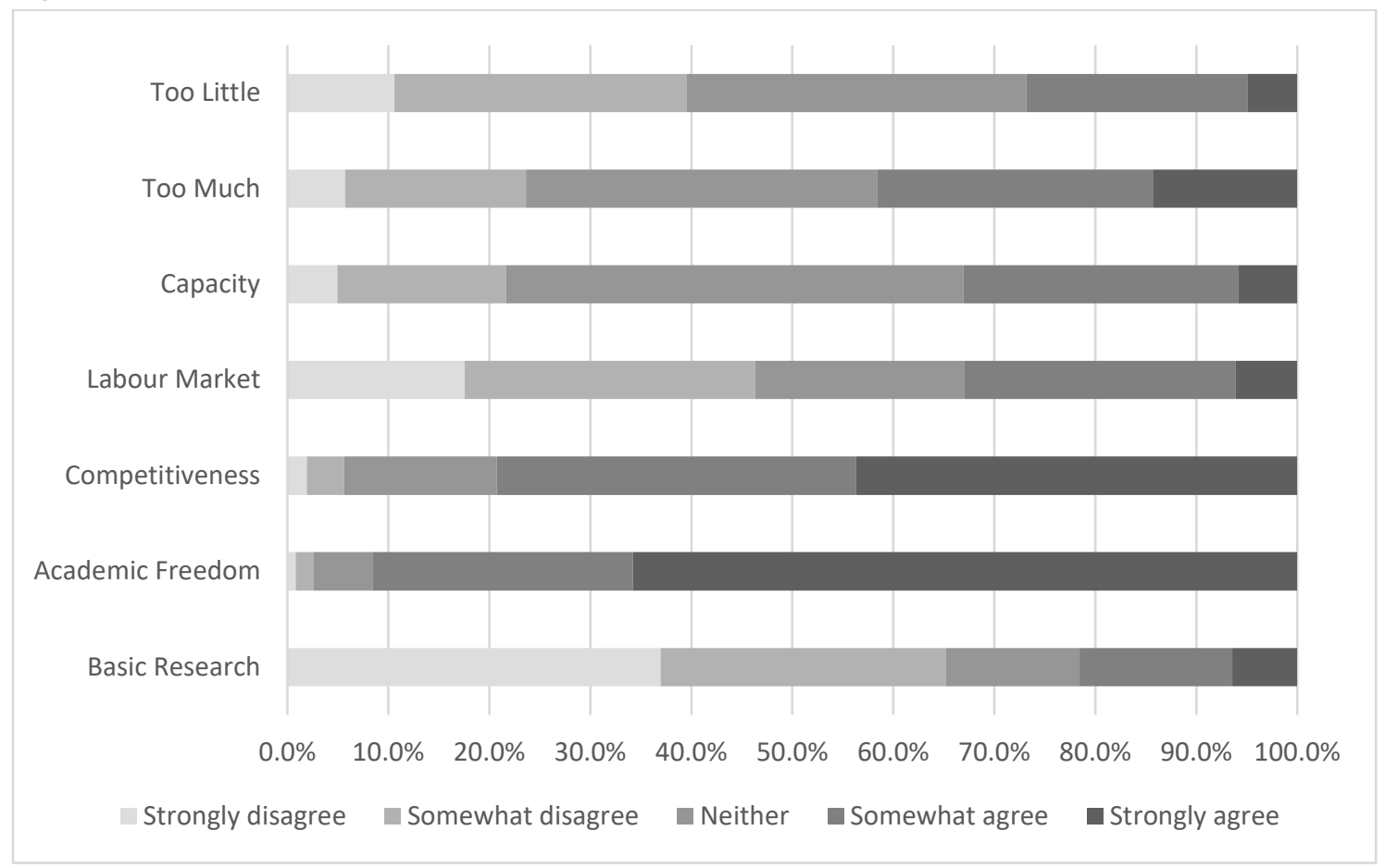

The distribution of responses to this question is displayed in Figure 1. The largest proportion of academics are strongly supportive of the importance of academic freedom and the smallest proportion are supportive of the notion that academic research ought to be aloof from application. However, there is considerable variety in responses, with some academics in strong agreement and some in strong disagreement with each of the statements, in line with evidence of persistent variety in attitudes towards the third mission on campuses (Philpott et al. 2011). Importantly, while we examine the antecedents of agreement with each of these statements in turn, we believe that relative agreement with items 1,2 and 6 is indicative of reticence towards third mission ideals. In contrast, relative agreement with items 3, 4 and 7 may indicate greater enthusiasm for a more utilitarian view of universities and for third mission ideals. Item 5 seems more difficult to interpret. Indeed, simple correlation analysis supports our intuition that item 5 doesn't correlate with either a pro- or anti-mission disposition. Moreover, factor analysis returns a single unrotated factor solution, with items 1,2 and 6 loading positively and items 3,4 and 7 loading negatively ${ }^{5}$. Following this we construct a simple summary variable by summing items 3,4 and 7 and the inverse (i.e. $6-x_{i}$, where $x_{i}$ is the response to a specific item by respondent i) of items 1,2 and 6 . This variable may range from 6-30 and we take it to indicate relative disposition towards the notion of a university third mission ${ }^{6}$. This, then, becomes our eighth dependent variable.

\section{Table 1 Descriptive Statistics}

\footnotetext{
${ }^{5}$ See Appendix A1 for these elementary analyses.

${ }^{6}$ Item 5 is set aside, since it appears to correlate poorly with the other items. The results are largely the same when we repeating our analysis with item 5 included. These are not reported here, given space constraints, but are available from the authors on request.
} 


\begin{tabular}{|c|c|c|c|c|c|}
\hline \multicolumn{2}{|l|}{ Discipline } & \multicolumn{2}{|c|}{ Research Focus } & \multicolumn{2}{|l|}{ Position } \\
\hline Health Science & $18.63 \%$ & No research & $6.40 \%$ & Retired & $4.09 \%$ \\
\hline Bio \& Chemistry & $13.17 \%$ & Basic & $24.61 \%$ & Full Professor & $18.96 \%$ \\
\hline Physics and Maths & $13.33 \%$ & User-inspired basic & $24.41 \%$ & Associate Professor & $31.74 \%$ \\
\hline Engineering & $7.75 \%$ & Applied & $40.38 \%$ & Assistant Professor & $21.84 \%$ \\
\hline Social Sciences & $30.81 \%$ & Other & $4.20 \%$ & Research Fellow & $18.22 \%$ \\
\hline \multirow[t]{2}{*}{ Arts \& Humanities } & $16.31 \%$ & & & Research Assistant & $3.06 \%$ \\
\hline & & & & Teaching Fellow & $2.10 \%$ \\
\hline \multicolumn{2}{|c|}{$N=16,717$} & \multicolumn{2}{|c|}{$\mathrm{N}=18,117$} & \multicolumn{2}{|r|}{$N=18117$} \\
\hline \multicolumn{2}{|l|}{ Gender } & \multicolumn{2}{|l|}{ Experience } & \multicolumn{2}{|l|}{ Age } \\
\hline Male & $58.06 \%$ & SME & $24.68 \%$ & Under 30 & $4.36 \%$ \\
\hline \multirow[t]{5}{*}{ Female } & $41.93 \%$ & Entrepreneur & $15.22 \%$ & $30-39$ & $27.09 \%$ \\
\hline & & Large Company & $22.90 \%$ & $40-49$ & $26.74 \%$ \\
\hline & & Public Sector & $28.64 \%$ & 50 and over & $40.87 \%$ \\
\hline & & Charity & $12.33 \%$ & & \\
\hline & $=18,176$ & & $V=18,177$ & & $N=18,008$ \\
\hline
\end{tabular}

We are fortunate that the survey records a range of information on what might be interpreted broadly as the human capital of respondents. We believe that these data allow us to construct a credible model of faculty attitudes and to test our hypotheses. Descriptive statistics for these independent variables are recorded in table 1. In addition, the survey provides information on academics' perceptions of the factors that influence career advancement. Specifically, respondents were asked to rate 5 factors on a 5-point scale, ranging from "completely unimportant" to "very important". The relative strength of these factors is likely to indicate important local norms that will, in turn, influence attitudes (Tartari, Perkmann, and Salter 2014). These data are displayed in figure 2. The primacy of research is evident (Lockett, Kerr, and Robinson 2008), as is the existence of variety. Although research is considered to be "important" or "very important" for career advancement and promotion by a little over $90 \%$ of the sample, other factors appear to 'matter' to different extents. In our analyses, we create 5 dummy variables coded a ' 1 ' if the respondent considers that factor to be either "important" or "very important" and ' 0 ' otherwise. 
Figure 2 Factors influencing career advancement

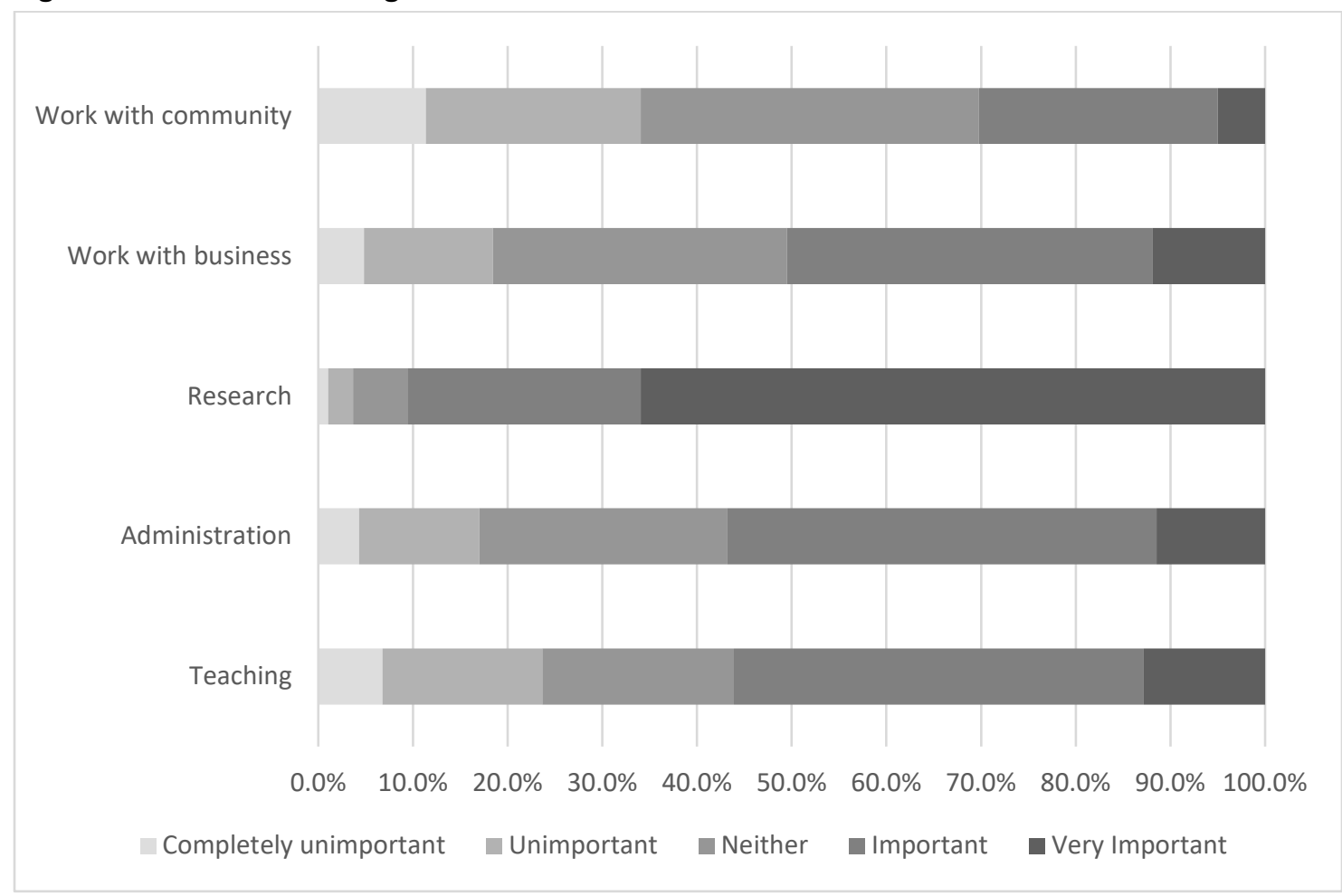

\section{Results}

To test our hypotheses, we estimate a series of 7 ordered logit regressions, 1 for each of the attitudinal statements outlined above. We also estimate a simple OLS of our third mission composite variable. The results of these estimations are recorded in tables $2 \mathrm{a}$ and $2 \mathrm{~b}$. For exposition purposes, table $2 \mathrm{a}$ presents the results of our three 'anti-mission' statements and our neutral statement ("Capacity"), while table 2b presents the results of our three 'pro-mission' statements and our composite measure. Table $2 \mathrm{~b}$ also records variance inflations factors estimated on the OLS model. The magnitudes of these give no cause for concern with respect to multicollinearity. For space reasons, we do not report a simple correlation matrix. However, unremarkably, the largest pairwise correlation is between age and rank: Spearman's rho of -0.5108 . No other pairwise correlations exceed 0.3 (or $10 \%$ of shared variance) ${ }^{7}$.

For the ordered logit models, we report odds ratios. These are obtained by exponenting the ordered logit coefficients. These are interpreted as the effect of a one-unit change on the predictor variable of the odds of being in group greater than $k$ versus the odds of being in group less than or equal to $k$, where $k$ is the response on the dependent variable. In simple terms, odds ratios of greater than 1 are indicative or stronger agreement, those less than 1 are indicative of weaker agreement.

\footnotetext{
${ }^{7}$ The exception is the variables concerning perceptions of career advancement influencers. Here teaching and administration have a pairwise correlation of 0.525 , while working with business and working with community has a pairwise correlation of 0.499 . Neither or these give cause for concern.
} 
Table 2a Ordered logit estimations of attachment to ideals

\begin{tabular}{|c|c|c|c|c|}
\hline Variable & 1. Basic Research & 2. Academic Freedom & 6. Too Far & 5. Capacity \\
\hline \multicolumn{5}{|l|}{ Discipline } \\
\hline Medicine & $0.774(0.035)^{* * *}$ & $0.676(0.033)^{* * *}$ & $0.832(0.036)^{* * *}$ & $0.937(0.042)$ \\
\hline Bio\&Chem & $1.274(0.064)^{* * *}$ & $0.759(0.043)^{* * *}$ & $0.842(0.042)^{* * *}$ & $0.918(0.047)$ \\
\hline Phys\&Math & $1.630(0.081)^{* * *}$ & $0.922(0.054)$ & $0.935(0.047)$ & $1.027(0.052)$ \\
\hline Engineering & $1.272(0.078)^{* * *}$ & $0.608(0.041)^{* * *}$ & $0.779(0.048)^{* * *}$ & $1.308(0.835)^{\text {*** }}$ \\
\hline Arts & $1.666(0.076)^{* * *}$ & $1.481(0.086)^{* * *}$ & $1.659(0.076)^{* * *}$ & $0.920(0.042)$ \\
\hline \multicolumn{5}{|l|}{ Position } \\
\hline Retired & $1.216(0.099)^{b}$ & $1.412(0.143)^{* * *}$ & $0.907(0.073)$ & $1.288(0.106)^{* *}$ \\
\hline Full Professor & $0.805(0.042)^{* * *}$ & $1.280(0.078)^{* * *}$ & $0.697(0.035)^{* * *}$ & $1.182(0.061)^{* * *}$ \\
\hline Assoc. Professor & $0.908(0.038)^{* *}$ & $1.064(0.051)$ & $0.888(0.037)^{* *}$ & $1.057(0.044)$ \\
\hline Research Fellow & $0.909(0.044)^{* *}$ & $0.930(0.050)$ & $0.873(0.041)^{* *}$ & $0.994(0.048)$ \\
\hline Research Assist. & $0.871(0.081)$ & $0.829(0.082)^{*}$ & $0.925(0.082)$ & $1.005(0.092)$ \\
\hline Teaching Fellow & $0.821(0.090)^{*}$ & $0.887(0.105)$ & $0.899(0.094)$ & $0.983(0.103)$ \\
\hline \multicolumn{5}{|l|}{ Research Focus } \\
\hline No research & $1.338(0.089)^{* * *}$ & $0.648(0.045)^{* * *}$ & $0.867(0.056)^{* *}$ & $0.889(0.059)$ \\
\hline Basic & $4.422(0.182)^{* * *}$ & $1.773(0.086)^{* * *}$ & $2.220(0.089)^{* * *}$ & $1.061(0.043)$ \\
\hline User-inspired & $1.975(0.076)^{* * *}$ & $1.438(0.063)^{* * *}$ & $1.478(0.056)^{* * *}$ & $1.146(0.044)^{\text {*** }}$ \\
\hline Other & $2.276(0.169)^{* * *}$ & $0.993(0.087)$ & $1.428(0.107)^{* * *}$ & $1.005(0.075)$ \\
\hline \multicolumn{5}{|l|}{ Age } \\
\hline Under 30 & $0.751(0.062)^{* * *}$ & $0.579(0.051)^{* * *}$ & $0.907(0.072)$ & $0.605(0.050)^{* * *}$ \\
\hline $30-39$ & $0.889(0.039)^{* *}$ & $0.886(0.044)^{* *}$ & $0.697(0.035)$ & $0.693(0.030)^{* * *}$ \\
\hline $40-49$ & $0.912(0.035)^{* *}$ & $0.881(0.039)^{* *}$ & $1.004(0.038)$ & $0.867(0.033)^{* * *}$ \\
\hline \multicolumn{5}{|l|}{ Gender } \\
\hline Female & $0.759(0.024)^{* * *}$ & $0.775(0.028)^{* * *}$ & $0.986(0.030)$ & $0.875(0.028)^{* * *}$ \\
\hline \multicolumn{5}{|l|}{ Experience } \\
\hline SME & $0.921(0.033)^{* *}$ & $0.928(0.038)^{*}$ & $0.936(0.033)^{*}$ & $0.957(0.035)$ \\
\hline Entrepreneur & $0.749(0.033)^{* * *}$ & $1.012(0.049)$ & $0.728(0.031)^{* * *}$ & $1.160(0.050)^{* * *}$ \\
\hline Large firm & $0.899(0.303)^{* *}$ & $0.843(0.034)^{* * *}$ & $0.732(0.026)^{* * *}$ & $1.147(0.042)^{* * *}$ \\
\hline PSO & $0.844(0.032)^{* * *}$ & $0.844(0.032)^{* * *}$ & $0.978(0.032)$ & $0.996(0.038)$ \\
\hline Charity & $0.955(0.044)$ & $1.160(0.061)^{* *}$ & $1.228(0.054)^{* * *}$ & $0.968(0.046)$ \\
\hline \multicolumn{5}{|l|}{ Incentives } \\
\hline Teaching & $0.901(0.030)^{* * *}$ & $0.927(0.036)^{*}$ & $0.772(0.026)^{* * *}$ & $0.879(0.030)^{\text {*** }}$ \\
\hline Administration & $1.022(0.034)$ & $1.168(0.045)^{* * *}$ & $1.153(0.038)^{* * *}$ & $0.971(0.033)$ \\
\hline Research & $0.878(0.043)^{* *}$ & $1.210(0.068)^{* * *}$ & $0.685(0.034)^{* * *}$ & $0.773(0.039)^{* * *}$ \\
\hline Business & $0.947(0.031)$ & 1.015 (0.039) & $1.267(0.041)^{* * *}$ & $0.979(0.033)$ \\
\hline Community & $0.896(0.033)^{* *}$ & $0.978(0.041)$ & $0.908(0.033)^{* *}$ & $0.919(0.034)^{* *}$ \\
\hline $\operatorname{LR} \chi^{2}$ & 2889.67 & 1049.95 & 1391.79 & 438.47 \\
\hline $\mathrm{N}$ & 15,945 & 15,945 & 15,945 & 15,945 \\
\hline
\end{tabular}

Odds ratios and coefficients in parenthesis. Superscripts ${ }^{* * *},{ }^{* *}$ and ${ }^{*}$ indicate statistical significance at the $1 \%, 5 \%$ and $10 \%$ levels respectively. 
Our first hypothesis anticipated disciplinary variations in attitudes towards the role of universities. Specifically, we expected faculty members in the arts and humanities to be least attached to ideals that are consistent with the third mission, while faculty in engineering, health and the physical sciences would be most likely to be pro-third mission. Our results largely confirm this hypothesis. In our estimations, social scientists are our reference group. Faculty members in the arts and humanities were significantly most likely to agree with our three 'anti-mission' statements (table 2a) and significantly least likely to agree with the three 'pro-mission' statements (table 2b). This is also reflected in the final regression on the composite measure, where being an arts and humanities faculty member is significantly negatively associated with a positive disposition toward third mission ideals. The opposite pattern is broadly apparent for faculty members in health, biology and chemistry and engineering; with engineering faculty, in particular, more likely to believe in universities' contribution to competitiveness and to labour markets and with the statement that they have done too little to increase their relevance and usefulness. This is, again, reflected in our composite third mission regression.

Our second hypothesis concerned the influence of research focus on attitudes. Here we anticipated that applied and user-inspired research would associate with a stronger attachment to pro-mission consistent ideals. Again, with applied research as our reference category, this is broadly what we find. Faculty members engaged in basic research were consistently most likely to agree with our 'anti-mission' statements and consistently least likely to agree with our 'pro-mission' statements. Indeed, a similar, though weaker, pattern was observed for user-inspired and 'other' researchers. In short, and as hypothesised, faculty engaged in applied research are significantly more likely to hold pro-mission attitudes. As expected, this is also reflected in the composite regression on third mission attitudes.

However, our estimations also reveal an intriguing finding. Our categorisation includes those faculty members not engaged in research (6.4\% of the sample). This group is typically ignored in discussions of the third mission. Yet they appear, on balance, more pro-mission than even those scientists engaged in applied research. Their neglect in third mission narratives may relate to the tendency for both research and practice on academic entrepreneurship, specifically, and knowledge transfer, more generally, to concentrate on a select group of scientists, in specific faculties, often engaged in funded research. But it may hint at underutilised capacity and we return to this issue in our discussions.

Our third hypothesis was concerned with age and rank. Here we anticipated that younger and more junior academics would be more pro-mission. In our estimations, we find no clear evidence to support this hypothesis. In our composite third mission estimation, there is tentative evidence that the youngest academics are more likely to hold pro-mission attitudes. However, those between 30-39 years old are tentatively indicated to hold less pro-mission attitudes. Examining the estimations on each individual statement, it would seem that this is largely driven by generally lower strength of belief in younger academics. Younger academics are consistently less likely to hold the strongest beliefs on academic freedom and basic research, but also on the role of universities in competitiveness. It is not that younger academics are more or less likely to associate with third mission ideals. Rather, they are less likely to hold strong and entrenched views. 
Table $2 \mathrm{~b}$ Ordered logit and OLS estimations of attachment to ideals

\begin{tabular}{|c|c|c|c|c|c|}
\hline Variable & 3. Competitiveness & 4. Labour Markets & 7. Too Little & Third Mission & VIF \\
\hline \multicolumn{6}{|l|}{ Discipline } \\
\hline Medicine & $1.307(0.056)^{* * *}$ & $1.244(0.056)^{* * *}$ & $0.898(0.039)^{* *}$ & $0.612(0.078)^{* * *}$ & 1.40 \\
\hline Bio\&Chem & $1.505(0.073)^{* * *}$ & $2.116(0.111)^{* * *}$ & $0.796(0.039)^{* * *}$ & $0.504(0.088)^{* * *}$ & 1.35 \\
\hline Phys\&Math & $1.132(0.056)^{* *}$ & $1.775(0.922)^{* * *}$ & $0.701(0.034)^{* * *}$ & $-0.118(0.088)$ & 1.35 \\
\hline Engineering & $2.053(0.124)^{* * *}$ & $2.454(0.164)^{* * *}$ & $0.822(0.050)^{* * *}$ & $0.897(0.108)^{* * *}$ & 1.25 \\
\hline Arts & $0.541(0.025)^{* * *}$ & $0.769(0.036)^{* * *}$ & $0.616(0.029)^{* * *}$ & $-1.500(0.081)^{* * *}$ & 1.38 \\
\hline \multicolumn{6}{|l|}{ Position } \\
\hline Retired & $0.844(0.068)^{* *}$ & $1.077(0.091)$ & $0.993(0.081)$ & $-0.246(0.145)^{*}$ & 1.25 \\
\hline Full Professor & $0.784(0.039)^{* * *}$ & $1.346(0.072)^{* * *}$ & $0.769(0.039)^{* * *}$ & $0.086(0.090)$ & 1.90 \\
\hline Assoc. Professor & $0.951(0.039)$ & $1.130(0.049)^{* *}$ & $0.968(0.040)$ & $0.110(0.074)$ & 1.80 \\
\hline Research Fellow & $0.847(0.040)^{* * *}$ & $0.934(0.046)$ & $1.078(0.039)$ & $0.059(0.085)$ & 1.66 \\
\hline Research Assist. & $0.932(0.083)$ & $0.899(0.082)$ & $1.148(0.102)$ & $0.212(0.161)$ & 1.18 \\
\hline Teaching Fellow & $0.995(0.105)$ & $1.125(0.123)$ & $1.240(0.129)^{* *}$ & $0.360(0.189)^{*}$ & 1.11 \\
\hline \multicolumn{6}{|l|}{ Research Focus } \\
\hline No research & $1.521(0.100)^{* * *}$ & $0.934(0.062)$ & $1.052(0.037)$ & $0.373(0.116)^{* * *}$ & 1.17 \\
\hline Basic & $0.656(0.026)^{* * *}$ & $0.670(0.028)^{* * *}$ & $0.627(0.025)$ & $-2.346(0.071)^{* * *}$ & 1.40 \\
\hline User-inspired & $0.773(0.029)^{* * *}$ & $0.903(0.036)^{* *}$ & $0.790(0.030)$ & $-1.097(0.067)^{* * *}$ & 1.26 \\
\hline Other & $0.798(0.059)^{* *}$ & $0.681(0.053)^{* * *}$ & $0.840(0.063)$ & $-1.141(0.134)^{* * *}$ & 1.13 \\
\hline \multicolumn{6}{|l|}{ Age } \\
\hline Under 30 & $0.956(0.076)$ & $0.677(0.055)^{* * *}$ & $1.080(0.085)$ & $0.272(0.144)^{*}$ & 1.29 \\
\hline $30-39$ & $0.928(0.039)^{*}$ & $0.779(0.035)^{* * *}$ & $0.924(0.039)^{*}$ & $-0.129(0.076)^{*}$ & 1.76 \\
\hline $40-49$ & $1.044(0.039)$ & $0.899(0.053)^{* *}$ & $0.880(0.033)^{* *}$ & $0.011(0.067)$ & 1.36 \\
\hline \multicolumn{6}{|l|}{ Gender } \\
\hline Female & $1.149(0.035)^{* * *}$ & $0.742(0.024)^{* * *}$ & $1.021(0.032)$ & $0.257(0.055)^{* * *}$ & 1.14 \\
\hline \multicolumn{6}{|l|}{ Experience } \\
\hline SME & $1.079(0.038)^{* *}$ & $1.128(0.042)^{* * *}$ & $1.052(0.037)$ & $0.230(0.063)^{* * *}$ & 1.16 \\
\hline Entrepreneur & $1.214(0.051)^{* * *}$ & $1.336(0.060)^{* * *}$ & $1.269(0.054)^{* * *}$ & $0.713(0.075)^{* * *}$ & 1.11 \\
\hline Large firm & $1.186(0.042)^{* * *}$ & $1.205(0.045)^{* * *}$ & $1.117(0.040)^{* *}$ & $0.581(0.064)^{* * *}$ & 1.11 \\
\hline PSO & $0.978(0.322)$ & $0.944(0.033)^{*}$ & $1.048(0.035)$ & $0.174(0.059)^{* *}$ & 1.12 \\
\hline Charity & $0.821(0.036)^{* * *}$ & $0.755(0.035)^{* * *}$ & $1.050(0.047)$ & $-0.308(0.079)^{* * *}$ & 1.07 \\
\hline \multicolumn{6}{|l|}{ Incentives } \\
\hline Teaching & $1.285(0.042)^{* * *}$ & $1.232(0.043)^{* * *}$ & $0.937(0.031)^{* *}$ & $0.436(0.059)^{* * *}$ & 1.32 \\
\hline Administration & $0.954(0.031)$ & $1.028(0.035)$ & $0.984(0.032)$ & $-0.173(0.059)^{* *}$ & 1.30 \\
\hline Research & $0.930(0.046)$ & $1.050(0.054)$ & $0.760(0.037)^{* * *}$ & $0.022(0.088)$ & 1.06 \\
\hline Business & $1.066(0.034)^{* *}$ & $1.242(0.042)^{* * *}$ & $0.852(0.028)^{* * *}$ & $-0.063(0.058)$ & 1.29 \\
\hline Community & $1.335(0.048)^{* * *}$ & $1.156(0.044)^{* * *}$ & $0.870(0.032)^{* * *}$ & $0.305(0.065)^{* * *}$ & 1.34 \\
\hline $\operatorname{LR} \chi^{2}$ & 1454.32 & 1341.16 & 760.09 & & \\
\hline$R^{2}$ & & & & 0.178 & \\
\hline $\mathrm{N}$ & 15,945 & 15,945 & 15,945 & 15,945 & \\
\hline
\end{tabular}


Odds ratios and coefficients in parenthesis. Superscripts ${ }^{* * *},{ }^{* *}$ and ${ }^{*}$ indicate statistical significance at the $1 \%, 5 \%$ and $10 \%$ levels respectively.

Our findings are similarly inconclusive on the issue of rank. The composite model does offer a weak indication that retired academics are less likely to be pro-mission, while the most junior of staff (those on temporary teaching only contracts) are more likely to be pro-mission. These groups represent around $4 \%$ and $2 \%$ of the sample respectively and the reference group is lecturers/assistant professors. This latter group, almost $22 \%$ of the sample, were the real focus of our hypothesis. It is in this group that we anticipated that the literature on academic entrepreneurship and engagement confused propensity with proclivity, and that more junior academics were more likely to hold pro-mission beliefs (Ambos et al. 2008). However, as with age, we find no support for this hypothesis. Again, examination of the individual statement estimations suggests that lecturers simply hold less strong beliefs, in relation to professors in particular. For instance, professors are shown to more strongly believe in the primacy of academic freedom and in the centrality of higher education to competitiveness; and to less strongly believe that universities have gone too far to meet the needs of industry or have done too little to make themselves relevant to society.

On the balance of a large empirical literature that suggests that female academics are less likely to engage in a broad range of entrepreneurial and commercial activities (Hmieleski and Powell 2018), our fourth hypothesis anticipated that female academics would be less likely to espouse attachment to third mission ideals. Our evidence rejects this hypothesis. Indeed, it would seem that female academics are more likely to hold strong pro-mission ideals. This is shown in the composite measure regression and in the individual statement regressions. Holding other factors constant, female academics are less likely to hold the strongest views on basic research or academic freedom; and most likely to hold the strongest views on the role of universities in preparing students for labour markets. Set against this, female academics are also less likely to strongly believe in the importance of higher education for competitiveness. Based on an analysis of statement 6 ("too far") from the 2009 iteration of this survey, Abreu and Grinevich (2017) suggest that female academics are more ambivalent, rather than more antipathetic, than male academics on the issue or research commercialisation. Our findings may be interpreted in a similar manner. However, they also indicate the potential misalignment of attitudes and opportunities and of unexploited capacity. We return to this issue in or discussions.

Our fifth hypothesis concerned the role of external experience in fostering pro third mission attitudes. Our evidence overwhelmingly supports the hypothesis. Prior experiences as an entrepreneur, in a large firm and in a SME are all positively associated with our composite measure. They are all also positively associated with the individual pro-mission items and negatively associated with the anti-mission items; with the exception of entrepreneurial experience and belief in academic freedom. Here, there is no evidence that academics with entrepreneurial experience are any less likely to value academic freedom. While this requires further exploration, our intuition is that this relates to the value placed upon independence by entrepreneurs, which has been shown to persist in academic entrepreneurs (Shane 2004). Independence and freedom are proximate concepts in the entrepreneurship literature (e.g. Hessels, Van Gelderen, and Thurik 2008). One intriguing finding is that those who have had experience 
working for charities or not-for-profits are significantly less likely to hold pro-mission attitudes. Since the proportion of these individuals is almost as high as those with entrepreneurial experience, this is not a trivial group. Indeed, given the increasing interest in social entrepreneurship on campuses (Siegel and Wright 2015), this may be an important group in meeting a broader entrepreneurial agenda than has typically been formulated. Again, we return to this issue in our discussions.

Finally, we hypothesised that academics working at institutions where either research or teaching dominated career advancement, would be less likely to report attachment to third mission ideals. This is the notion that the third mission is being crowded out by universities' first and second missions (Koryakina, Sarrico, and Teixeira 2015). We find no support for this hypothesis. Indeed, academics who believe that their institution values teaching are more likely to hold pro-mission beliefs; both in composite and across the individual statements. A similar pattern is observed for those whose institutions reward community engagement. The findings for academics who disproportionately believe that their institutions value research above other factors are more mixed. Perhaps predictably, these academics most strongly believe in academic freedom and least strongly in the notion that industry has insufficient receptor capacity for academic research. However, they also least strongly agree with the statements that universities have gone too far to meet industry's needs or have done too little to be relevant to society or contribute to economic development. Taken as a whole, we believe that the findings on incentives' influence on attitudes serve to underscore the variety of institutions for higher education (Philpott et al. 2011; Kitagawa, Sánchez Barrioluengo, and Uyarra 2016). Universities are not undifferentiated parts of national systems of innovation, but are frequently specialised to meet local needs and to contribute to local development objectives (e.g. Braunerhjelm 2008; Wright 2014). Whilst historically discussion on academic entrepreneurship have focused on leading universities, star scientists and a narrow range of activities (e.g. spin-offs, patenting and licencing), Siegel and Wright $(2015$, p. 585$)$ note a "move to focus on more indirect aspects of academic entrepreneurship, such as social ventures and commercial start-ups launched by students and alumni, as well as the transfer of knowledge to existing local businesses". It is likely that locally or regionally-specialised universities have a greater role to play here. Again, we return to this issue in closing.

\section{Concluding remarks}

This study examined faculty attitudes towards ideals that are (in)consistent with universities' third mission. Our goal was to better understand how different career profiles, personal characteristics, and perspectives on career development explained dispositions towards, or away from, third mission principles. Our analyses draw on extensive data collected as part of the Survey of Knowledge Exchange Activity by UK Academics (2012-2015) (Hughes et al. 2017). We analysed the data using a series of ordered logit regressions of (dis)agreement with seven statements on the role of universities, and with a simple OLS model where the dependent variable was a composite measure intended to indicate broad sympathy with third mission ideals.

Our results reveal several intriguing insights. In line with prior work (Goldstein 2010), we observe a heterogeneity of faculty attitudes toward the third mission. Perhaps most notably, we observe that faculty members who are not engaged in research, and who are often overlooked in discussions of the third mission, appear more pro-mission than even those scientists engaged in applied research (i.e. the group 
typically seen as central to accomplishing the third mission). The implications of this are likely to be threefold.

First, it suggests underutilised capacity with the potential to make significant contributions to the third mission. This is also suggested by our findings on the positive disposition of female academics and those working at universities where teaching has a larger part to play in career advancement.

Second, and related to this, it implicates the broadening nature of entrepreneurial activity on campuses (Siegel and Wright 2015). As most of us will recognise, a significant part of university entrepreneurship is more closely linked to teaching than research. It is bound up in new venture creation courses, business plan competitions, student societies, alumni relations and, increasingly, enthusiasm for social entrepreneurship and social innovation. However, "the importance of student entrepreneurship has received far less attention than it likely deserves" (Grimaldi et al. 2011, p. 1047). )It rarely touches upon technology transfer offices and it is poorly captured by standard metrics of academic entrepreneurship, such as spin-offs, patents or license agreements. Fully articulating this broader perspective may further increase capacity. For instance, our finding that faculty members who have had experience working for charities and non-profits are significantly less likely to hold pro-mission attitudes raises the question as to whether they would be more inclined to engage with the third mission were greater emphasis placed upon social, rather than economic development. Enlargement of the third mission beyond regional and local economic development activities into social development activities may induce greater engagement amongst this group of academics.

Finally, the heterogeneity of attitudes across scientists is unlikely to be evenly distributed across institutions. That is, some universities will be better suited to some third mission activities and some will be better suited to others (and some may be unsuited to any, given current governance and rewards systems). In short, one size is unlikely to fit all (Philpott et al. 2011; Perkmann et al. 2013). Yet, "despite their heterogeneous backgrounds and institutional differences, universities seem to be under a financial policy pressure to adopt similar practices" (Kitagawa, Sánchez Barrioluengo, and Uyarra 2016, p.736). In many jurisdictions, universities are subject to "isomorphic forces", resulting from centralised research evaluation and resource allocation processes. This is certainly true in the UK, where the Research Excellence Framework (REF) looms large. Indeed, evidence suggests that, despite the availability of an extensive set of metrics on knowledge exchange activity, centralised funding continues to privilege a much narrower range, and commercialisation in particular (Rossi and Rosli 2015). This is remarkable. Empirical studies are consistent in painting a picture of a highly diverse higher education sector (see, for example Hewitt-Dundas 2012; Huggins and Kitagawa 2012 in the UK), with little sense of convergence. With respect to the third mission, universities appear to vary in at least three ways: the blend of activities that they undertakes; the types of partners engaged; and, the geographic scope of the activities (Kitagawa, Sánchez Barrioluengo, and Uyarra 2016).

This persistent heterogeneity ought, in turn, to convince stakeholders that conversations that conflate science commercialization with academic entrepreneurship, and situate this as at the heart of universities' third mission, almost certainly neglect the larger part of entrepreneurial activities undertaken within the higher education system. This narrative leads to the privileging of star scientists and a narrow range of activities. Of greater concern, it concentrates resources and opportunities - both within the higher education system, towards particular 'types' of institutions, and within individual universities, towards particular individuals and activities. And it is not clear that such concentration inevitably results in the greatest social or economic gains (Audia and Goncalo 2007; O'kane et al. 2015). 
In this light, one might argue that resources and opportunities disproportionately flow to academic insiders. This, rather than dispositions, may explain patterns of activity. For instance, there is longstanding evidence that male, tenured and research grant active academics are significantly more likely to engage in both formal and informal technology transfer (e.g. Shane 2004; Link, Siegel, and Bozeman 2007). Yet, at least in the current sample, there is limited evidence of a particular proclivity for entrepreneurship on their part. Rather, the most fertile ground may be found amongst the 'outsiders'; those engaged primarily in teaching, early career academics and female academics.

For individual universities, our findings suggest the need to reflect upon the strategies for resource allocation and entrepreneurial responsibility that underpin the pursuit of the third mission. Universities play "complicated and disparate roles" in their innovation systems that lead, in turn, to a wide variety of strategies for encouraging third mission activities (Grimaldi et al. 2011, p. 1047). This variety is underpinned by a range of factors, including institutional and departmental culture, institutional quality and the quality of academic leadership, and by the munificence and dynamism of the local economy.

In the face of this variety, it is tempting to elide guidance altogether. However, studies on the changing role of principal investigators ( $\mathrm{PI})$, that recount analogous pressures on funding, sense of identity and 'utility', provide useful areas for managerial and policy attention. For instance, as Mangematin and colleagues (2014) observe, "the emergence of new roles comes hand and hand with tensions" (p. 4). Faculty members are trained for one set of activities - teaching and researching - but are increasingly being asked to become active 'brokers' between science and society, and between science and industry. They are rarely provided with formal training to either act as brokers or to manage the organisational politics that often accompany it. The PI literature points to the role of tailored incentives, of transparent resource allocation, of informal and formal career-management support, and of capability building (Cunningham et al. 2016).

In many ways, we believe that academic entrepreneurship is analogous to corporate entrepreneurship. To this end, Wolcott and Lippitz (2007) usefully elaborate two dimensions that distinguish varieties of approaches to corporate entrepreneurship: resource ownership and entrepreneurial responsibility. Resources may be dedicated or ad hoc and responsibility may be focused or diffused (Figure 3). Here, there are parallels to Degroof and Roberts (2004) observations on academic spinoff environments; noting that in developed entrepreneurial environments universities may adopt a passive strategy, confident that the community will select the best projects and allocate sufficient resources. However, in weaker entrepreneurial contexts, universities may have to more actively develop procedures and structures to evaluate and select projects and to set aside specific resources. Rather like Wolcott and Lippitz (2007), the issues are concerned with where entrepreneurial responsibility resides and whether resources must be dedicated or ad hoc. Beyond this, the central issue is that the variety of third mission activities observed in related studies (Abreu and Grinevich 2012) and the current evidence of potential underexploited capacity call for a more considered approach to third mission strategy setting. We believe that the framework developed by Wolcott and Lippitz (2007) may be useful starting point. 
Figure 3 Four Modes of Corporate Entrepreneurship (Wolcott and Lippitz 2007)

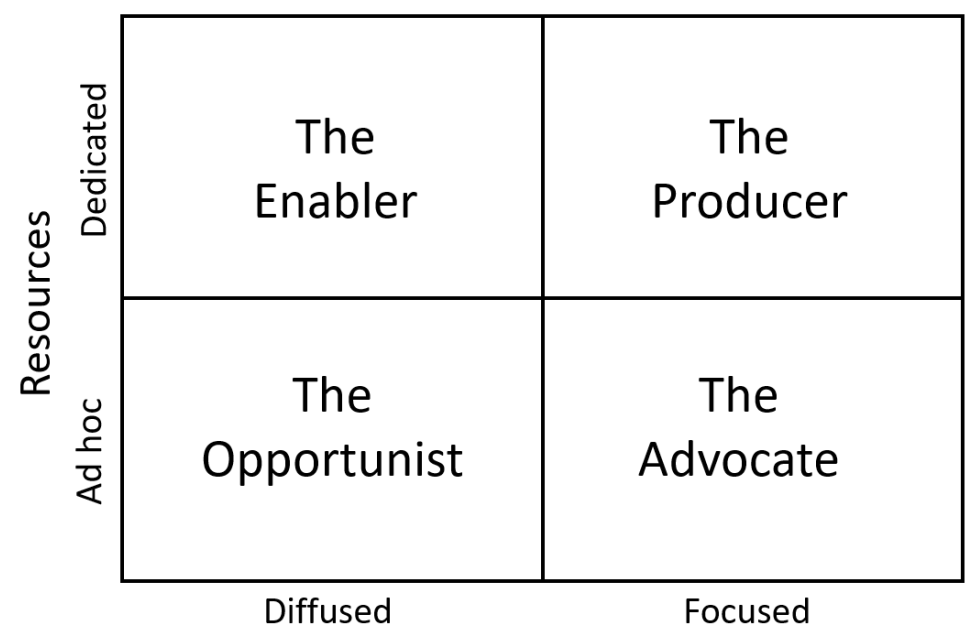

Responsibility for Entrepreneurship

In brief, whilst two or more approaches often co-exist within a single organisation, the broad implication is that, as organisations look to build sustained and sustainable corporate entrepreneurship, responsibility is likely to become more focused and dedicated pots of resources will be set aside (Wolcott and Lippitz 2007). However, out intuition is that universities will benefit most from a diffused responsibility for entrepreneurship. Our findings suggest that third mission capacities may be found in previously neglected places. The opportunist and enabler models seem to be a natural starting point for engaging the groups of academics who are pro-mission but lack necessary resources and opportunities. To be effective, these approaches require a high trust environment. Moreover, the enabler model requires that university administrators provide dedicated resources with transparent processes for resource access, active senior management support, and incentives and rewards that recognise the breadth of the third mission.

In summary, third mission activities are much broader than traditional science-based activities; they involve many more people, roles and activities. Many of which are informal, occasional or ad hoc and, thus, more difficult to measure (Secundo et al., 2017). As a result, many of these activities are poorly resourced and ineffectively used in assessing academic performance (Kapetaniou and Lee, 2017; Secundo et al., 2017). Manifesting third mission breadth in resource allocation decisions, incentives and rewards scheme is likely to be critical to engaging a larger cross-section of faculty members. We interpret our analyses to suggest that universities need to reflect upon the range of activities they want to promote and support under the third mission. Moreover, they need to do this in light of their unique resource endowments, science bases (Mustar et al., 2006) and local development contexts (Kapetaniou and Lee, 2017; Meissner and Shmatko, 2017; Perkmann et al., 2013). As de la Torre, and colleagues (2018, p. 14) insist, "since HEls are so different, they cannot be expected to respond in the same way to [centralised] incentives".

Of course, this institutional variety underscores a weakness in the study. In the early parts of the paper, we stressed the strength of our micro-level data. It is individual scientists that undertake third mission activities and studies of their attitudes are remarkably rare. However, engagement - in type, in extent and with whom - appears to vary somewhat systematically across institutions. Hewitt-Dundas (2012), for 
instance, notes differences between high and low research intensity UK institutions; with the former more likely to develop and exploit intellectual property and to partner with stakeholders outside their home region. In contrast, low research intensity institutions are more likely to be concerned with human capital development and to partner locally. There is little doubt that, despite isomorphic policy pressures (Kitagawa, Sánchez Barrioluengo, and Uyarra 2016), universities continue to exhibit strong heterogeneity in their approach to a third mission. University systems are historically contingent and individual universities have evolved with different organisational legacies that bear on institutional cultures and priorities and that will be manifest in governance structures, incentive systems and balance of academic disciplines. A small amount of this will be captured by the perspectives of individuals on their institution's incentive system. However, individual dispositions are likely to be shaped by other institutional factors.

Unfortunately, this data was not available in the current analysis. Analysis that embeds the individual within the institution is an important next step. In particular, we are enthusiastic about the possibilities of further exploring the link between individual and institutional dispositions. For instance, do particular types of individuals gravitate towards particular types of institutions, reinforcing patterns of resource allocation and knowledge exchange? Does this, in turn, lead to rigidities in implementation of third mission strategies? Parts of the literature has lamented the emergence of compliance and acquiescence, and the loss of creativity among academics in the face of third mission pressures (e.g. Oleksiyenko 2018). Other have raised concerns that insufficient resources for exploratory research will result in reactive strategies for research and engagement (O'Kane et al. 2015). Understanding how the interplay between individual and institutional aspirations influence this outcome is likely to be key to explicating the difference between universities that engage in entrepreneurial activities and truly entrepreneurial universities (Sam and Van Der Sijde 2014).

Other areas of future research may revolve around the increasing incidence of social entrepreneurial activities on campus or the role of students as a dynamic flow of entrepreneurial capital. In the former case, we observe particular antipathy for the third mission amongst those with experience working in charities and not-for-profits. It seems likely that an explicit articulation of the role of universities' third missions in contributing to the development of social capital, as well as financial capital, would help engage more academics; especially outside of the disciplines traditionally considered to be the source of academic entrepreneurship. In the latter case, student entrepreneurship, there exists an abundance of work exploring entrepreneurial education, but it has largely been concerned with the relationship between education and intentions (see, for example, the reviews by Pittaway and Cope 2007; Bae et al. 2014). Of more interest, here, might be the recursive relationship between successful student entrepreneuring and academic and institutional dispositions. In a version of Merton's (1968) "Matthew effect", might we find that success breeds success, such that individual's and institution's dispositions towards student-centred third mission strategies is founded on recognition of successful student (or alumni) entrepreneurs? Of course, there are likely to be a great many more fruitful research questions that rest on recognition of the contingency of successful third mission strategies and that explore the various bases of that contingency. We hope to contribute to some of these and to be enlightened by the work of others. 


\section{References}

Abreu, Maria, Pelin Demirel, Vadim Grinevich, and Mine Karataş-Özkan. 2016. "Entrepreneurial Practices in Research-Intensive and Teaching-Led Universities." Small Business Economics 47 (3): 695-717.

Abreu, Maria, and Vadim Grinevich. 2012. "The Nature of Academic Entrepreneurship in the UK: Widening the Focus on Entrepreneurial Activities." Research Policy. http://www.sciencedirect.com/science/article/pii/S0048733312002326.

- - . 2014. "Academic Entrepreneurship in the Creative Arts." Environment and Planning C: Government and Policy 32 (3): 451-470.

- - - 2017. "Gender Patterns in Academic Entrepreneurship." The Journal of Technology Transfer 42 (4): 763-794.

Ambos, Tina C., Kristiina Mäkelä, Julian Birkinshaw, and Pablo d'Este. 2008. "When Does University Research Get Commercialized? Creating Ambidexterity in Research Institutions." Journal of Management Studies 45 (8): 1424-1447.

Audia, Pino G., and Jack A. Goncalo. 2007. "Past Success and Creativity over Time: A Study of Inventors in the Hard Disk Drive Industry." Management Science 53 (1): 1-15.

Audretsch, David B. 2014. "From the Entrepreneurial University to the University for the Entrepreneurial Society." The Journal of Technology Transfer 39 (3): 313-321.

Bae, Tae Jun, Shanshan Qian, Chao Miao, and James O. Fiet. 2014. "The Relationship between Entrepreneurship Education and Entrepreneurial Intentions: A Meta-Analytic Review." Entrepreneurship Theory and Practice 38 (2): 217-254.

Bekkers, R., and I. M Bodas Freitas. 2008. "Analysing Knowledge Transfer Channels between Universities and Industry: To What Degree Do Sectors Also Matter?" Research Policy 37 (10): 1837-1853.

Benneworth, Paul, Harry de Boer, and Ben Jongbloed. 2015. "Between Good Intentions and Urgent Stakeholder Pressures: Institutionalizing the Universities' Third Mission in the Swedish Context." European Journal of Higher Education 5 (3): 280-296.

Bercovitz, Janet, and Maryann Feldman. 2008. "Academic Entrepreneurs: Organizational Change at the Individual Level." Organization Science 19 (1): 69-89.

Braunerhjelm, Pontus. 2008. "Specialization of Regions and Universities: The New versus the Old." Industry and Innovation 15 (3): 253-275.

Bruneel, Johan, Pablo d'Este, and Ammon Salter. 2010. "Investigating the Factors That Diminish the Barriers to University-Industry Collaboration." Research Policy 39 (7): 858-868.

Calderini, Mario, Chiara Franzoni, and Andrea Vezzulli. 2007. "If Star Scientists Do Not Patent: The Effect of Productivity, Basicness and Impact on the Decision to Patent in the Academic World." Research Policy 36 (3): 303-319.

Carayol, Nicolas. 2007. "Academic Incentives, Research Organization and Patenting at a Large French University." Econ. Innov. New Techn. 16 (2): 119-138.

Casati, Anne, and Corine Genet. 2014. "Principal Investigators as Scientific Entrepreneurs." The Journal of Technology Transfer 39 (1): 11-32.

Chantler, Abigail. 2016. "The Ivory Tower Revisited." Discourse: Studies in the Cultural Politics of Education 37 (2): 215-229.

Clarysse, Bart, Valentina Tartari, and Ammon Salter. 2011. "The Impact of Entrepreneurial Capacity, Experience and Organizational Support on Academic Entrepreneurship." Research Policy 40 (8): 1084-1093.

Colyvas, Jeannette A., Kaisa Snellman, Janet Bercovitz, and Maryann Feldman. 2012. "Disentangling Effort and Performance: A Renewed Look at Gender Differences in Commercializing Medical School Research." The Journal of Technology Transfer 37 (4): 478-489. 
Cunningham, James A., Vincent Mangematin, Conor O'Kane, and Paul O’Reilly. 2016. “At the Frontiers of Scientific Advancement: The Factors That Influence Scientists to Become or Choose to Become Publicly Funded Principal Investigators." The Journal of Technology Transfer 41 (4): 778-797.

David, Paul A. 2002. "The Political Economy of Public Science: A Contribution to the Regulation of Science and Technology." In The Regulation of Science and Technology, 33-57. Springer.

Degroof, Jean-Jacques, and Edward B. Roberts. 2004. "Overcoming Weak Entrepreneurial Infrastructures for Academic Spin-off Ventures." The Journal of Technology Transfer 29 (3-4): 327-352.

D'Este, P., and P. Patel. 2007. "University-Industry Linkages in the UK: What Are the Factors Underlying the Variety of Interactions with Industry?" Research Policy 36 (9): 1295-1313.

D'este, Pablo, and Markus Perkmann. 2011. "Why Do Academics Engage with Industry? The Entrepreneurial University and Individual Motivations." The Journal of Technology Transfer 36 (3): 316-339.

Dietz, James S., and Barry Bozeman. 2005. "Academic Careers, Patents, and Productivity: Industry Experience as Scientific and Technical Human Capital." Research Policy 34 (3): 349-367.

Etzkowitz, Henry. 2002. "MIT and the Rise of Entrepreneurial Science."

Fritsch, Michael, and Stefan Krabel. 2012. "Ready to Leave the Ivory Tower?: Academic Scientists' Appeal to Work in the Private Sector." The Journal of Technology Transfer 37 (3): 271-296.

Goethner, Maximilian, Martin Obschonka, Rainer K. Silbereisen, and Uwe Cantner. 2012. "Scientists' Transition to Academic Entrepreneurship: Economic and Psychological Determinants." Journal of Economic Psychology 33 (3): 628-641.

Goldstein, Harvey A. 2010. "The 'Entrepreneurial Turn'and Regional Economic Development Mission of Universities." The Annals of Regional Science 44 (1): 83.

Grimaldi, Rosa, Martin Kenney, Donald S. Siegel, and Mike Wright. 2011. "30 Years after Bayh-Dole: Reassessing Academic Entrepreneurship." Research Policy 40 (8): 1045-1057.

Grimpe, Christoph, and Heide Fier. 2010. "Informal University Technology Transfer: A Comparison between the United States and Germany." The Journal of Technology Transfer 35 (6): 637-650.

Guerrero, Maribel, James A. Cunningham, and David Urbano. 2015. "Economic Impact of Entrepreneurial Universities' Activities: An Exploratory Study of the United Kingdom." Research Policy 44 (3): 748-764.

Haeussler, Carolin, and Jeannette A. Colyvas. 2011. "Breaking the Ivory Tower: Academic Entrepreneurship in the Life Sciences in UK and Germany." Research Policy 40 (1): 41-54.

Hessels, Jolanda, Marco Van Gelderen, and Roy Thurik. 2008. "Entrepreneurial Aspirations, Motivations, and Their Drivers." Small Business Economics 31 (3): 323-339.

Hewitt-Dundas, Nola. 2012. "Research Intensity and Knowledge Transfer Activity in UK Universities." Research Policy 41 (2): 262-275.

Hmieleski, Keith M., and E. Erin Powell. 2018. "The Psychological Foundations of University Science Commercialization: A Review of the Literature and Directions for Future Research." Academy of Management Perspectives 32 (1): 43-77.

Horta, Hugo, and João M. Santos. 2016. "An Instrument to Measure Individuals' Research Agenda Setting: The Multi-Dimensional Research Agendas Inventory." Scientometrics 108 (3): 12431265.

Hoye, Kate, and Fred Pries. 2009. "'Repeat Commercializers,'the 'Habitual Entrepreneurs' of UniversityIndustry Technology Transfer." Technovation 29 (10): 682-689.

Huggins, Robert, and Fumi Kitagawa. 2012. "Regional Policy and University Knowledge Transfer: Perspectives from Devolved Regions in the UK." Regional Studies 46 (6): 817-832. 
Hughes, Alan, Cornelia Lawson, Ammon Salter, Michael Kitson, Anna Bullock, and Robert Hughes. 2016. "The Changing State of Knowledge Exchange: UK Academic Interactions with External Organizations 2005-2015."

Iorio, Roberto, Sandrine Labory, and Francesco Rentocchini. 2017. "The Importance of Pro-Social Behaviour for the Breadth and Depth of Knowledge Transfer Activities: An Analysis of Italian Academic Scientists." Research Policy 46 (2): 497-509.

Jain, Sanjay, Gerard George, and Mark Maltarich. 2009. "Academics or Entrepreneurs? Investigating Role Identity Modification of University Scientists Involved in Commercialization Activity." Research Policy 38 (6): 922-935.

Kitagawa, Fumi, Mabel Sánchez Barrioluengo, and Elvira Uyarra. 2016. "Third Mission as Institutional Strategies: Between Isomorphic Forces and Heterogeneous Pathways." Science and Public Policy 43 (6): 736-750.

Koryakina, Tatyana, Cláudia S. Sarrico, and Pedro N. Teixeira. 2015. "Third Mission Activities: University Managers' Perceptions on Existing Barriers." European Journal of Higher Education 5 (3): 316330.

Krabel, Stefan, and Pamela Mueller. 2009. "What Drives Scientists to Start Their Own Company?: An Empirical Investigation of Max Planck Society Scientists." Research Policy 38 (6): 947-956.

Labory, Sandrine, Roberto lorio, and Francesco Rentocchini. 2015. "Distinguishing between Breadth and Depth of Knowledge Transfer Activities: The Predominance of Third Mission Motives for Italian Scientists." In DRUID15 Conference on the Relevance of Innovation, Rome, Italy.

Lam, Alice. 2011. "What Motivates Academic Scientists to Engage in Research Commercialization:'Gold', 'Ribbon'or 'Puzzle'?” Research Policy 40 (10): 1354-1368.

Link, Albert N., Donald S. Siegel, and Barry Bozeman. 2007. "An Empirical Analysis of the Propensity of Academics to Engage in Informal University Technology Transfer." Industrial and Corporate Change 16 (4): 641-655.

Lockett, Nigel, Ron Kerr, and Sarah Robinson. 2008. "Multiple Perspectives on the Challenges for Knowledge Transfer between Higher Education Institutions and Industry." International Small Business Journal 26 (6): 661-681.

Loi, Michela, and Maria Chiara Di Guardo. 2015. "The Third Mission of Universities: An Investigation of the Espoused Values." Science and Public Policy 42 (6): 855-870.

Mangematin, Vincent, Paul O'Reilly, and James Cunningham. 2014. "PIs as Boundary Spanners, Science and Market Shapers." The Journal of Technology Transfer 39 (1): 1-10.

Merton, Robert K. 1942. "A Note on Science and Democracy." J. Legal \& Pol. Soc. 1: 115.

- - . 1968. "The Matthew Effect in Science: The Reward and Communication Systems of Science Are Considered." Science 159 (3810): 56-63.

Nelson, Richard R. 2001. "Observations on the Post-Bayh-Dole Rise of Patenting at American Universities." The Journal of Technology Transfer 26 (1-2): 13-19.

O'kane, Conor, James Cunningham, Vincent Mangematin, and Paul O’Reilly. 2015. “Underpinning Strategic Behaviours and Posture of Principal Investigators in Transition/Uncertain Environments." Long Range Planning 48 (3): 200-214.

Oleksiyenko, Anatoly. 2018. "Zones of Alienation in Global Higher Education: Corporate Abuse and Leadership Failures." Tertiary Education and Management 24 (3): 193-205.

Owen-Smith, Jason, and Walter W. Powell. 2001. "Careers and Contradictions: Faculty Responses to the Transformation of Knowledge and Its Uses in the Life Sciences." In The Transformation of Work, 109-140. Emerald Group Publishing Limited.

Perkmann, Markus, Valentina Tartari, Maureen McKelvey, Erkko Autio, Anders Broström, Pablo D’Este, Riccardo Fini, Aldo Geuna, Rosa Grimaldi, and Alan Hughes. 2013. "Academic Engagement and 
Commercialisation: A Review of the Literature on University-Industry Relations." Research

Policy 42 (2): 423-442.

Philpott, Kevin, Lawrence Dooley, Caroline O'Reilly, and Gary Lupton. 2011. "The Entrepreneurial University: Examining the Underlying Academic Tensions." Technovation 31 (4): 161-170.

Pinheiro, Rómulo, Patricio V. Langa, and Attila Pausits. 2015. "The Institutionalization of Universities' Third Mission: Introduction to the Special Issue." European Journal of Higher Education 5 (3): 227-232.

Pittaway, Luke, and Jason Cope. 2007. "Entrepreneurship Education: A Systematic Review of the Evidence." International Small Business Journal 25 (5): 479-510.

Rolfo, Secondo, and Ugo Finardi. 2014. "University Third Mission in Italy: Organization, Faculty Attitude and Academic Specialization." The Journal of Technology Transfer 39 (3): 472-486.

Rossi, Federica, and Ainurul Rosli. 2015. "Indicators of University-Industry Knowledge Transfer Performance and Their Implications for Universities: Evidence from the United Kingdom." Studies in Higher Education 40 (10): 1970-1991.

Sam, Chanphirun, and Peter Van Der Sijde. 2014. "Understanding the Concept of the Entrepreneurial University from the Perspective of Higher Education Models." Higher Education 68 (6): 891-908.

Sauermann, Henry, Wesley Cohen, and Paula Stephan. 2010. "Doing Well or Doing Good? The Motives, Incentives and Commercial Activities of Academic Scientists and Engineers." In DRUID Summer Conference, 200:16-18.

Shane, Scott Andrew. 2004. Academic Entrepreneurship: University Spinoffs and Wealth Creation. Edward Elgar Publishing.

Shane, Scott, Sharon AM Dolmans, Joseph Jankowski, Isabelle MMJ Reymen, and A. Georges L. Romme. 2015. "Academic Entrepreneurship: Which Inventors Do Technology Licensing Officers Prefer for Spinoffs?" The Journal of Technology Transfer 40 (2): 273-292.

Siegel, Donald S., and Mike Wright. 2015. “Academic Entrepreneurship: Time for a Rethink?" British Journal of Management 26 (4): 582-595.

Stephan, Paula E., Shiferaw Gurmu, Albert J. Sumell, and Grant Black. 2007. "Who's Patenting in the University? Evidence from the Survey of Doctorate Recipients." Econ. Innov. New Techn. 16 (2): 71-99.

Stokes, Donald E. 1997. "Pasteur's Quadrant: Basic Science and Technological Innovation 1997." The Brookings Institution.

Tartari, Valentina, Markus Perkmann, and Ammon Salter. 2014. "In Good Company: The Influence of Peers on Industry Engagement by Academic Scientists." Research Policy 43 (7): 1189-1203.

Tartari, Valentina, Ammon Salter, and Pablo D'Este. 2012. "Crossing the Rubicon: Exploring the Factors That Shape Academics' Perceptions of the Barriers to Working with Industry." Cambridge Journal of Economics 36 (3): 655-677.

Torre, Eva M. de la, Federica Rossi, and Marti Sagarra. 2018. "Who Benefits from HEls Engagement? An Analysis of Priority Stakeholders and Activity Profiles of HEls in the United Kingdom." Studies in Higher Education, 1-20.

Watermeyer, Richard. 2015. "Lost in the 'Third Space': The Impact of Public Engagement in Higher Education on Academic Identity, Research Practice and Career Progression." European Journal of Higher Education 5 (3): 331-347.

Wolcott, R. C, and M. J Lippitz. 2007. "The Four Models of Corporate Entrepreneurship." MIT Sloan Management Review 49 (1): 75.

Wright, Mike. 2014. "Academic Entrepreneurship, Technology Transfer and Society: Where Next?" The Journal of Technology Transfer 39 (3): 322-334.

\section{Appendix A1}


Correlation matrix of third mission items (Spearman's Rho)

\begin{tabular}{|l|r|r|r|r|r|r|r|}
\hline & \multicolumn{1}{|c|}{1} & \multicolumn{1}{c|}{2} & \multicolumn{1}{c|}{3} & \multicolumn{1}{c|}{4} & \multicolumn{1}{c|}{5} & \multicolumn{1}{c|}{6} & \multicolumn{1}{c|}{7} \\
\hline 1. Basic & 1.000 & & & & & & \\
\hline 2. Academic Freedom & 0.168 & 1.000 & & & & & \\
\hline 3. Competitiveness & -0.160 & 0.133 & 1.000 & & & & \\
\hline 4. Labour markets & -0.164 & -0.193 & 0.233 & 1.000 & & & \\
\hline 5. Capacity & 0.063 & 0.070 & 0.048 & 0.038 & 1.000 & & \\
\hline 6. Too much & 0.365 & 0.234 & -0.203 & -0.271 & 0.141 & 1.000 & \\
\hline 7. Too Little & -0.167 & -0.123 & 0.052 & 0.178 & 0.112 & -0.116 & 1.000 \\
\hline
\end{tabular}

Factor loadings

\begin{tabular}{|l|r|}
\hline Variable & Loading \\
\hline 1. Basic & 0.501 \\
\hline 2. Academic Freedom & 0.311 \\
\hline 3. Competitiveness & -0.317 \\
\hline 4. Labour markets & -0.451 \\
\hline 5. Capacity & 0.086 \\
\hline 6. Too much & 0.585 \\
\hline 7. Too Little & -0.285 \\
\hline
\end{tabular}

Factor analysis returned a single factor with an eigenvalue exceeding 1. 